\title{
Friendship networks and psychological well-being from late adolescence to young adulthood: a gender-specific structural equation modeling approach
}

\author{
Alexander Miething $^{1 *}$ D, Ylva B. Almquist ${ }^{2}$, Viveca Östberg ${ }^{2}$, Mikael Rostila $^{1,2}$, Christofer Edling $^{3}$ and Jens Rydgren ${ }^{1}$
}

\begin{abstract}
Background: The importance of supportive social relationships for psychological well-being has been previously recognized, but the direction of associations between both dimensions and how they evolve when adolescents enter adulthood have scarcely been addressed. The present study aims to examine the gender-specific associations between self-reported friendship network quality and psychological well-being of young people during the transition from late adolescence to young adulthood by taking into account the direction of association.

Methods: A random sample of Swedes born in 1990 were surveyed at age 19 and again at age 23 regarding their own health and their relationships with a maximum of five self-nominated friends. The response rate was $55.3 \%$ at baseline and $43.7 \%$ at follow-up, resulting in 772 cases eligible for analysis. Gender-specific structural equation modeling was conducted to explore the associations between network quality and well-being. The measurement part included a latent measure of well-being, whereas the structural part accounted for autocorrelation for network quality and for well-being over time and further examined the cross-lagged associations.
\end{abstract}

Results: The results show that network quality increased while well-being decreased from age 19 to age 23. Females reported worse well-being at both time points, whereas no gender differences were found for network quality. Network quality at age 19 predicted network quality at age 23, and well-being at age 19 predicted wellbeing at age 23. The results further show positive correlations between network quality and well-being for males and females alike. The strength of the correlations diminished over time but remained significant at age 23. Simultaneously testing social causation and social selection in a series of competing models indicates that while there were no cross-lagged associations among males, there was a weak reverse association between well-being at age 19 and network quality at age 23 among females.

Conclusions: The study contributes to the understanding of the direction of associations between friendship networks and psychological well-being from late adolescence to young adulthood by showing that while these dimensions are closely intertwined among males and females alike, females' social relationships seem to be more vulnerable to changes in health status.

Keywords: Social network, Psychological well-being, Friendship network quality, Late adolescence, Young adulthood, Gender, Structural equation modeling, Two-wave panel data, Sweden

\footnotetext{
* Correspondence: alexander.miething@sociology.su.se

1 Department of Sociology, Stockholm University, SE-106 91 Stockholm,

Sweden

Full list of author information is available at the end of the article
} 


\section{Background}

The importance of supportive social relationships has been confirmed for a wide range of health-related outcomes [1] and across various stages of the life course [2]. In late adolescence, associations with depression, psychological complaints and reduced psychological wellbeing have been documented [3, 4]. Depressive symptoms represent the most prevalent health problem in that age group in Sweden and other Western societies, particularly affecting females [5-8]. In Sweden, rates of psychological symptoms during late adolescence have increased continuously during the last three decades, especially among females $[9,10]$. A poor sense of well-being has been identified as a marker of more severe subsequent psychological problems: Some studies posit that emotional problems and reduced well-being experienced in adolescence may remain as chronic health problems and thus persist into and beyond young adulthood [11-13]. It has also been shown that reduced well-being is associated with a subsequent higher risk of depression, self-harm, substance abuse, and suicide [14].

The transition from late adolescence to young adulthood commonly marks a significant shift in young people's lives that includes leaving school and the parental home, as well as the engagement in new social contexts such as higher education or the labor market. During this period young people encounter new demands and responsibilities and are thus likely to experience increasingly more stressful situations. Friendships and social networks serve as important sources of social support that may help individuals to deal with the challenges that adult life entails and to alleviate the perception of stress $[15,16]$. Intense social interaction and highquality friendships may increase the ability to adjust to new social environments [17]. In this respect, friendships fulfill functions that family members often cannot adequately supply [17]. Moreover, successful social relationships enhance the individual's capacity to socialize and build further social contacts [17-20] and are thus considered protective against maladjustment [21].

The quality of friendships changes over the life span and tends to rise with increasing age. Adult-like highquality friendships - characterized by support, reciprocity, and intimacy - do not evolve until adolescence, and they become even more important as the individual enters young adulthood $[22,23]$. It has been shown that various aspects of friendship quality are correlated with mental health outcomes in middle and late adolescence [24]. Scholars have suggested that low-quality relations and the lack of positive interaction may elicit anxiety, which in turn affects the adolescents' social skills [19, 25]. The inhibited social functioning of the individual may then provoke withdrawal from peers that worsens wellbeing and leads to a further deterioration in social skills over time [19]. This cycle of bi-directional events already emerging in childhood and becoming more manifest during adolescence [26] - makes it difficult to disentangle the causes and consequences in the association between the individual's conditions and conditions in the peer group. A majority of past studies has maintained that induction is the predominant mechanism explaining the association between peer relations and mental health outcomes during adolescence [27]. The induction hypothesis suggests that peer groups influence the individual. Individuals tend to adapt to behaviors, norms, and attitudes extant in the peer group. This assumption, however, often relies on theoretical fundamentals rather than empirical evidence. In fact, at the near end of late adolescence, the direction of association appears to be reversed or at least reciprocal with both processes operating simultaneously: Due to older adolescents' improved capacity to regulate peer influences, induction tends to decline while peer selection increases [27]. For example, an anxious person is thought to seek contact with anxious peers. This notion has been empirically confirmed by Borelli and Prinstein [28], who showed that depressive adolescents seek negative feedback from peer groups [28].

Gender is an important aspect to be considered in relationship processes during adolescence. As cognitive, emotional and behavioral development differs between adolescent males and females, their interactions with others and the way they form social networks vary. Adolescent females are usually more engaged in prosocial interactions [29] and are better able to develop supportive relationships with friends [12, 22, 30]. Females' greater commitment and relational orientation may explain why they are better than males at mobilizing social support to master certain critical events [31]. However, earlier research demonstrated that males are more often found in disengaged peer groups, while females typically seek out higher commitment and relatedness in their best friendships [32]. As a consequence, females are thought to have a greater tendency to disrupt friendships [33] partially because they tend to react more strongly to the violation of social norms in network relations. Therefore, friendship disruption and in particular the distortion of otherwise protective social ties may turn into a disadvantage and make females more vulnerable to depressive symptoms because they potentially reinforce the perception of stress and discomfort [33, 34]. In addition, corumination, the behavior of excessively discussing and revisiting problems with friends, is more common among girls than boys and may confound the benefits of close peer relationships $[35,36]$. Females' tendency towards stronger social commitments suggests that the association between network quality and psychological well-being is more positive among females than males. However, problematic social interactions and distortions 
in friendships may have adverse effects and wipe out the positive associations between network quality and wellbeing.

\begin{abstract}
Aim and research questions
The current study seeks to examine changes in friendship network quality and psychological well-being from late adolescence to young adulthood as well as the direction of associations of these relationships. Based on literature and theories discussed above, it is hypothesized that:
\end{abstract}

H1: Friendship network quality and psychological wellbeing are positively correlated in late adolescence and young adulthood alike.

$\mathrm{H} 2$ : The association between friendship network quality and psychological well-being is more strongly pronounced among females, both in late adolescence and in young adulthood.

H3: Friendship network quality in late adolescence influences psychological well-being in young adulthood, reflecting a process of social causation.

H4: Psychological well-being in late adolescence influences friendship network quality in young adulthood, reflecting a process of social selection. H5: There are bi-directional associations between friendship network quality and psychological well-being from late adolescence to young adulthood, reflecting a reciprocal association between these dimensions. H6: The directionality of associations between friendship network quality and psychological well-being differs between females and males.

\section{Methods}

\section{Data material}

We use data from the Swedish survey Social Capital and Labor Market Integration: A Cohort Study, a twowave survey on social capital and personal networks. The first wave of data collection was undertaken in 2009 and included a random sample of 2500 Swedish citizens born in 1990 to native parents. Thus, the vast majority of the respondents were 19 years of age at the time of the interview. The respondents completed a questionnaire through telephone interviews conducted by Statistics Sweden. The response rate was $55.3 \%(n=1382)$. Inaccessibility was a major cause of non-response - an issue related to the widespread use of unregistered prepaid phones in this age group - and to a lesser extent an unwillingness to participate. The non-response rate was somewhat higher among males and among those who lived outside the metropolitan areas. It was also higher among individuals who had not finished upper secondary school and had lower school marks, as well as among those whose parents had a lower educational level [37]. The second wave of data collection was carried out in 2013, i.e., when most respondents were 23 years old. Of the initial sample, $43.7 \%$ responded to the questionnaire. The non-response pattern in terms of sociodemographic factors was similar to the first wave. The data material used in the current study is restricted to those individuals who participated in both waves and had full information on all study variables $(n=772)$. Compared to those who opted out, the remaining respondents had friendship networks of higher quality and better psychological well-being.

\section{Friendship network quality}

The interview contained questions about friendship networks. The respondents were asked to think of the five persons (referred to as 'alters') with whom they spend most of their spare time. In a clarifying statement, respondents were asked to think of this as 'friendship'. At Time 1 (T1), $8.3 \%$ of the alters were family members or romantic partners, whereas this figure had increased to $16.6 \%$ at Time 2 (T2). The distribution of the number of named alters was the following (here displayed as T1-T2): five alters, 58-56 \%; four alters, 15-14 \%; three alters, 18-19\%; two alters, 8-6\%; and one alter, $2-2 \%$. Acknowledging that peers may play multiple roles, and also that relatives and romantic partners may act as friends, all named peers were retained for the analysis. The respondents were subsequently asked about each one of their named alters, including a question related to the quality of the relationship: "How good do you think your relationship is?" There were five response options, ranging from 'Not good at all' (one point) to 'Very good' (five points). The measure of friendship network quality was derived by dividing the total number of points by the number of named alters. Thus, the measure indicates the average value of relationship quality within the network.

\section{Psychological well-being}

Six indicators of psychological well-being were included in the current study, namely: "I'm often tense and nervous" ('Tense'); "I often feel sad and down" ('Sad'); "I manage to do a lot" ('Energy'); "Overall, I'm happy" ('Happy'); "I'm mostly satisfied with myself" ('Pleased'); and "I'm often grouchy or irritated" ('Grouchy'). The response options were: 'Matches exactly' (1); 'Matches roughly' (2); 'Neither matches nor does not match' (3); 'Matches poorly' (4); and 'Does not match at all' (5). For the analysis, the response options for the positive statements were reversed. Hence, a higher value for any of the six items indicates better psychological well-being. When all six items were included in an exploratory factor analysis (EFA) with varimax orthogonal rotation (performed separately for each combination of gender 
and wave of data collection), only the one-factor solutions provided eigenvalues above one. The rotated factor loadings for the one-factor solutions ranged from .40 to .66 for males and from .45 to .73 for females at T1 whereas they ranged from .39 to .72 for males and .39 to .69 for females at T2 (Table 1). Moreover, Cronbach's alpha was .73 for males and .77 for females at T1, and .77 for males and .72 for females at $\mathrm{T} 2$.

\section{Results}

The distribution of friendship network quality and psychological well-being can be seen in Table 2. Note that higher values consistently correspond to higher friendship network quality and psychological well-being throughout the table. Gender differences were tested by means of independent sample t-tests, which showed that females have significantly worse well-being compared to males in terms of being tense and nervous, feeling sad and down, and not being pleased with themselves, at T1 and T2 alike. Moreover, at T1 they more often report that they are grouchy and irritated. There were no statistically significant gender differences for the remaining items. With regard to changes from T1 to T2, the results from paired samples t-tests show that friendship network quality improved slightly across the two time points, although this change was only statistically significant for females. Among males there were statistically significant increases in being tense and nervous, feeling sad and down, as well as feeling less pleased with oneself. For females, the only statistically significant change was seen for feeling grouchy and irritated, for which the reporting decreased over time. Although not shown in Table 2, it should be noted that the corresponding

Table 1 Factor loadings from exploratory factor analysis

\begin{tabular}{lllll}
\hline & Males & & Females & \\
& Factor 1 & Uniqueness & Factor 1 & Uniqueness \\
\hline Time 1 & & & & \\
Tense & 0.47 & 0.78 & 0.56 & 0.68 \\
Sad & 0.66 & 0.57 & 0.73 & 0.47 \\
Energy & 0.52 & 0.73 & 0.50 & 0.75 \\
Happy & 0.60 & 0.64 & 0.67 & 0.55 \\
Pleased & 0.65 & 0.58 & 0.64 & 0.59 \\
Grouchy & 0.40 & 0.84 & 0.45 & 0.79 \\
Time 2 & & & & \\
Tense & 0.52 & 0.73 & 0.46 & 0.79 \\
Sad & 0.71 & 0.50 & 0.69 & 0.53 \\
Energy & 0.58 & 0.67 & 0.48 & 0.77 \\
Happy & 0.68 & 0.53 & 0.64 & 0.59 \\
Pleased & 0.72 & 0.48 & 0.59 & 0.65 \\
Grouchy & 0.39 & 0.85 & 0.39 & 0.84 \\
\hline
\end{tabular}

gender differences and differences across time had been present also if the mean values of psychological wellbeing had been used (males T1: 4.20; females T1: 3.94; males T2: 4.11; females T2: 3.99). The gender differences were statistically significant at each time point. Moreover, the differences between $\mathrm{T} 1$ and $\mathrm{T} 2$ were statistically significant for males but not for females.

The gender-specific associations between friendship network quality and psychological well-being across the two time points were analyzed by means of structural equation modeling (SEM), with maximum likelihood estimation. As a first step, a baseline model was constructed with auto-regressive paths (measuring stability over time) from friendship network quality at T1 to T2 and from the latent factor psychological well-being at $\mathrm{T} 1$ to T2. Moreover, correlations between friendship network quality and psychological well-being were added at $\mathrm{T} 1$ and $\mathrm{T} 2$, respectively. Based on modification indices for omitted paths in the baseline model, some error terms for the well-being items were allowed to correlate (details available upon request).

Four competing models were subsequently tested, for males and females separately: the baseline model (Model 1); a social causation model, where friendship network quality at T1 predicts psychological well-being at T2 (Model 2); a social selection model, where psychological well-being at $\mathrm{T} 1$ predicts friendship network quality at T2 (Model 3); and a reciprocal model (Model 4). The models are illustrated in Fig. 1a-d.

A set of model fit statistics was derived for each of the four models: the Standardized Root Mean Square Residual (RMSEA), which should be below or close to 0.06 [38]; as well as the Comparative Fit Index (CFI) and the TuckerLewis Index (TLI), which both should be close to or above 0.95 [38]. The Akaike Information Criterion (AIC) and the Bayesian Information Criterion (BIC) were used to evaluate the relative goodness of fit, where lower values relative to the other models correspond to better fit [39]. Additionally, chi-square differences tests were performed to compare models that were hierarchically nested. The upper part of Table 3 shows the fit indices for males, whereas the lower part of the table gives the corresponding results for females. For males, all four models provide an acceptable fit to the data according to the values for RMSEA (.016-.018), CFI (.993-.995) and TLI (.991-.992). The baseline model (Model 1) has the lowest values for $\mathrm{AIC}$ and BIC. Moreover, the chi-square difference tests show that none of the other three models fit the data significantly better than Model 1 . With regard to females, the values for RMSEA (.051-.052), CFI (.948-.950), and TLI (.929-.931) indicate acceptable fit of all four models. AIC is lowest for the social selection model (Model 3), whereas the baseline model (Model 1) has the lowest BIC. According to the chi-square difference tests, Model 3 fits 
Table 2 Distribution of the study variables $(n=772)$

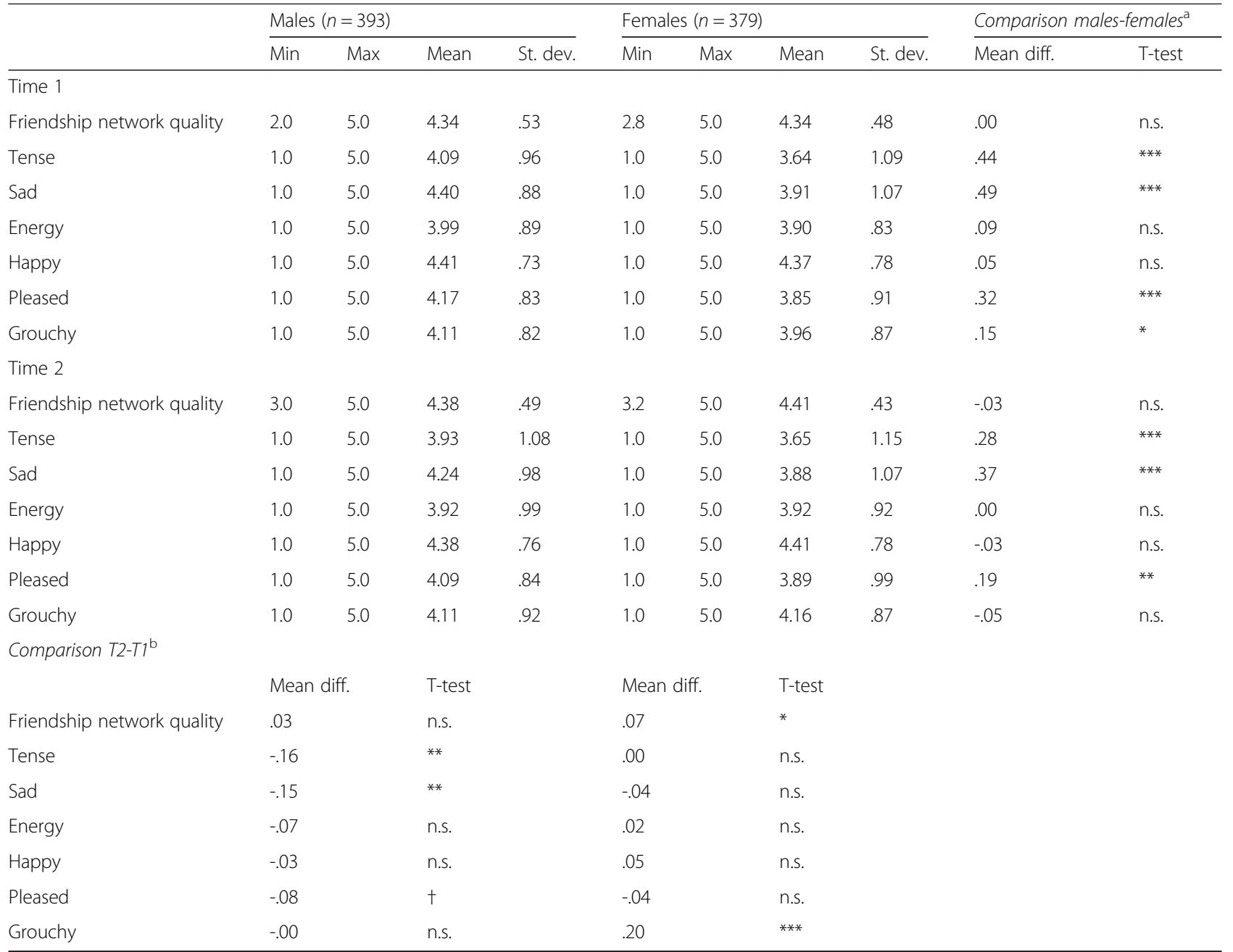

Note: higher values indicate better friendship network quality and psychological well-being (items 'Tense', 'Sad', and 'Grouchy' are reversed)

${ }^{a}$ A positive difference value reflects that males are better off compared to females, whereas a negative difference value suggests the opposite

${ }^{\mathrm{b}}$ A positive difference value indicates an improvement over time, whereas a negative difference value reflects the opposite

${ }^{* * *} p<.001,{ }^{* *} p<.01,{ }^{*} p<.05,{ }^{\dagger} p<.10$

the data significantly better than Model 1 , on condition that $p<0.10$ is considered an acceptable level. It should be noted here that Model 4 provides a significantly better fit for the data $(p=.08)$ compared to Model 2, but not compared to the other two models.

Based on the model fit statistics, it was decided to proceed with Model 1 for males and Model 3 for females. The results from structural equation modeling are shown in Fig. 2 (for clarity, the error terms have been omitted from the figure). Concerning the measurement model, i.e., the latent factors representing psychological well-being, the included items show factor loadings of .38-.67 for males and .44-.75 for females at Time 1, and .31-.70 for males and .29-.69 for females at Time 2. It should be noted that a step-wise removal of the items with the weakest loadings did not significantly improve the model fit (data not presented).
With regard to the autoregressive paths, the coefficient for friendship network quality is $.37(p<.001)$ for males and $.30(p<.001)$ for females. For psychological wellbeing, the stability coefficients are $.45(p<.001)$ and .55 $(p<.001)$ for males and females, respectively. Based on post-estimation procedure, it was shown that the stability of psychological well-being is significantly stronger than the stability of friendship network quality among females, whereas no such difference was found among males. Moreover, the correlation between friendship network quality and psychological well-being is .29 $(p<.001)$ for males and .28 $(p<.001)$ for females at Time 1 , as compared to $.15(p<.05)$ for males and $.17(p<.01)$ for females at Time 2. For both males and females, post-estimation showed that the correlation is significantly weaker at T2 than T1. Finally, since the social selection model proved to have the 
a Baseline (Model 1)

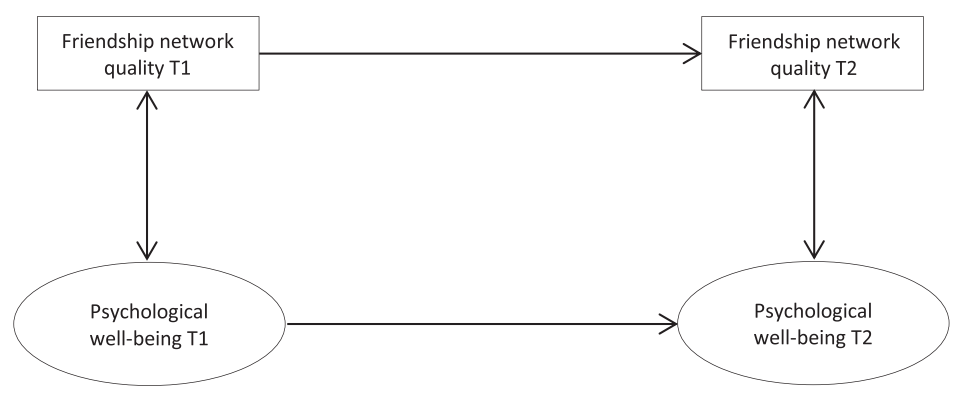

b Social causation (Model 2)

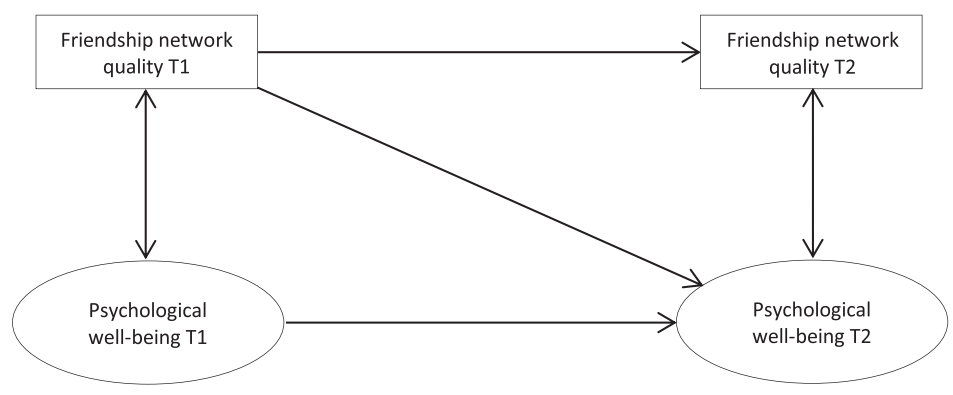

C Social selection (Model 3)

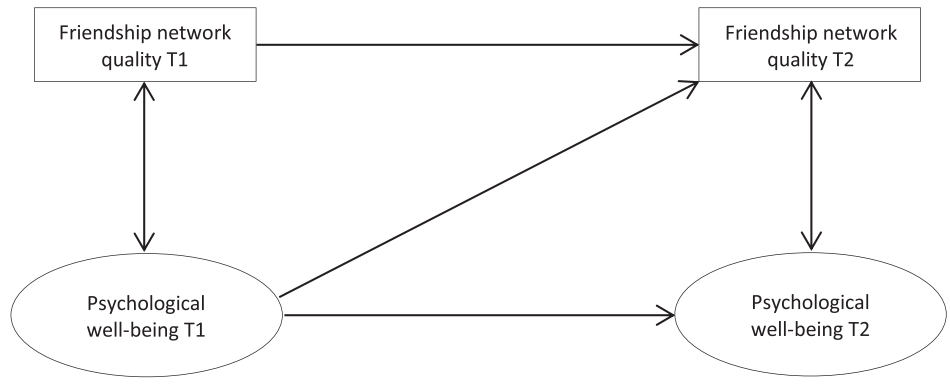

d Reciprocal (Model 4)

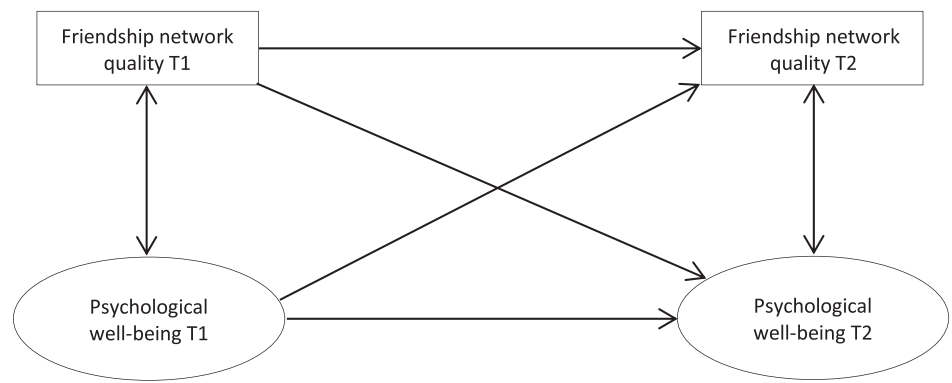

Fig. 1 a Baseline (Model 1). b Social causation (Model 2). c Social selection (Model 3). d Reciprocal (Model 4)

best fit among females, the figure includes a path from psychological well-being at Time 1 to friendship network quality at Time 2 . The coefficient of $.10(p<.10)$ suggests that better psychological wellbeing at T1 predicts an increase in females' friendship network quality from $\mathrm{T} 1$ to $\mathrm{T} 2$.

\section{Discussion}

The current study examines changes in friendship network quality and psychological well-being as well as the correlations between both measures across the transition period from late adolescence (age 19) to young adulthood (age 23). The use of structural equation modeling 
Table 3 Goodness-of fit statistics for the tested models ( $n=772$ )

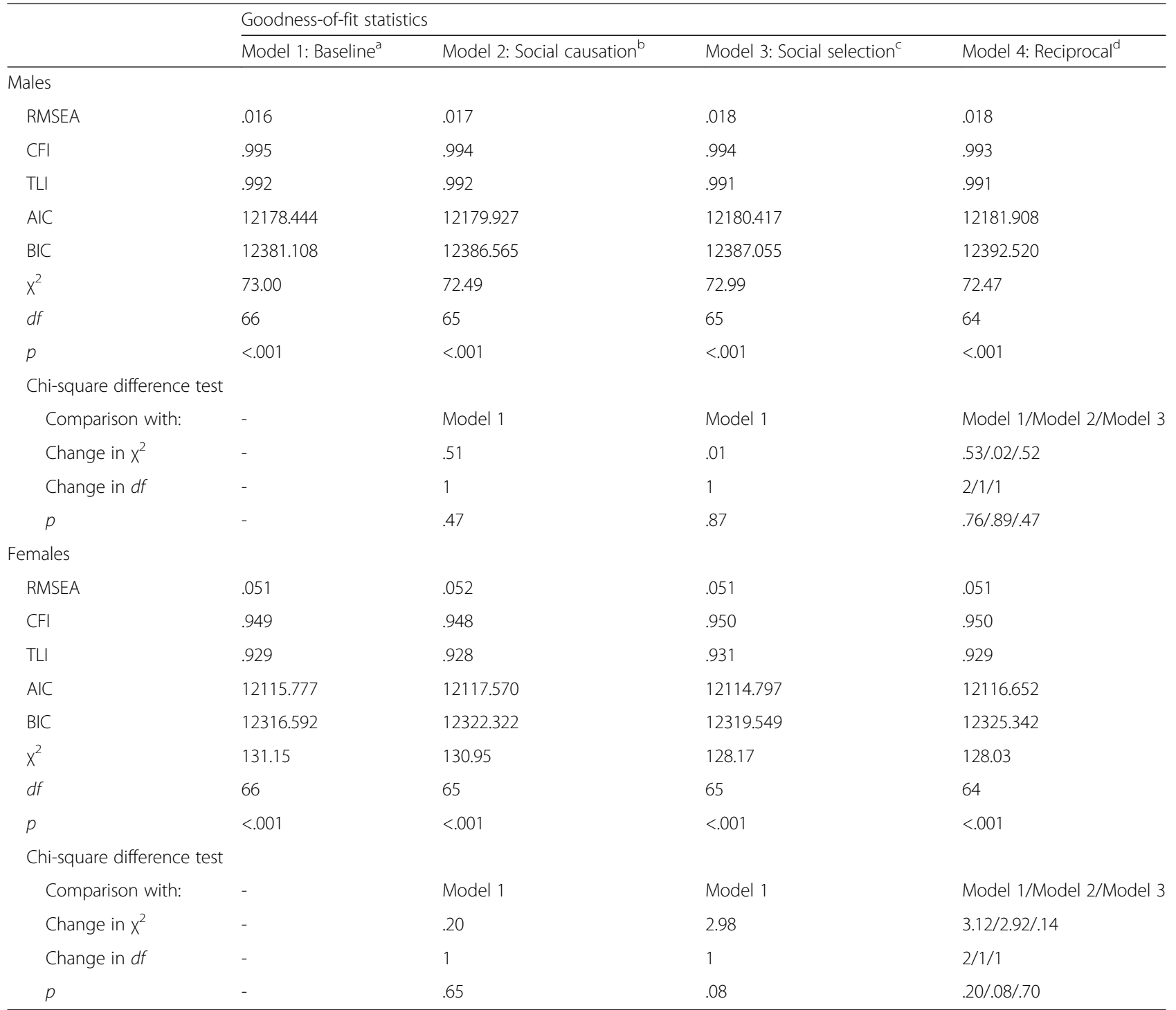

${ }^{a}$ Only auto-regressive associations and cross-sectional correlations

${ }^{b}$ Friendship network quality at $\mathrm{T} 1$ predicts psychological well-being at $\mathrm{T} 2$

c Psychological well-being at T1 predicts friendship network quality at T2

${ }^{d}$ Friendship network quality and psychological well-being have reciprocal associations

for longitudinal data made it possible to simultaneously investigate the social causation and social selection models of the association between network quality and well-being.

In line with prior research, the descriptive analysis demonstrated similar ratings of friendship network quality for males and females. Considering the transition into adulthood, females' perception of their friendship network quality slightly improved. This finding confirms previous research which has demonstrated upward ratings of perceived friendship quality across late adolescence [24]. Also in line with past studies, the comparison of indicators of well-being showed significant gender differences, to the disadvantage of females, which persisted throughout the transition into young adulthood. Females' salient high ratings on tenseness and sadness, for example, may further reveal their higher emotional vulnerability and reflect their increased propensity to suffer from psychological discomfort and depression [33, 40]. A comparison of the indicators of well-being between the two waves of data collection suggests that females' overall well-being remains relatively stable during the transition from adolescence to adulthood whereas males exhibited higher levels of tenseness and sadness at age 23 compared to age 19. These elevated negative aspects among males may point to an increasing occurrence of stress and lack of coping capacities after adolescence [5]. Unlike young females, 


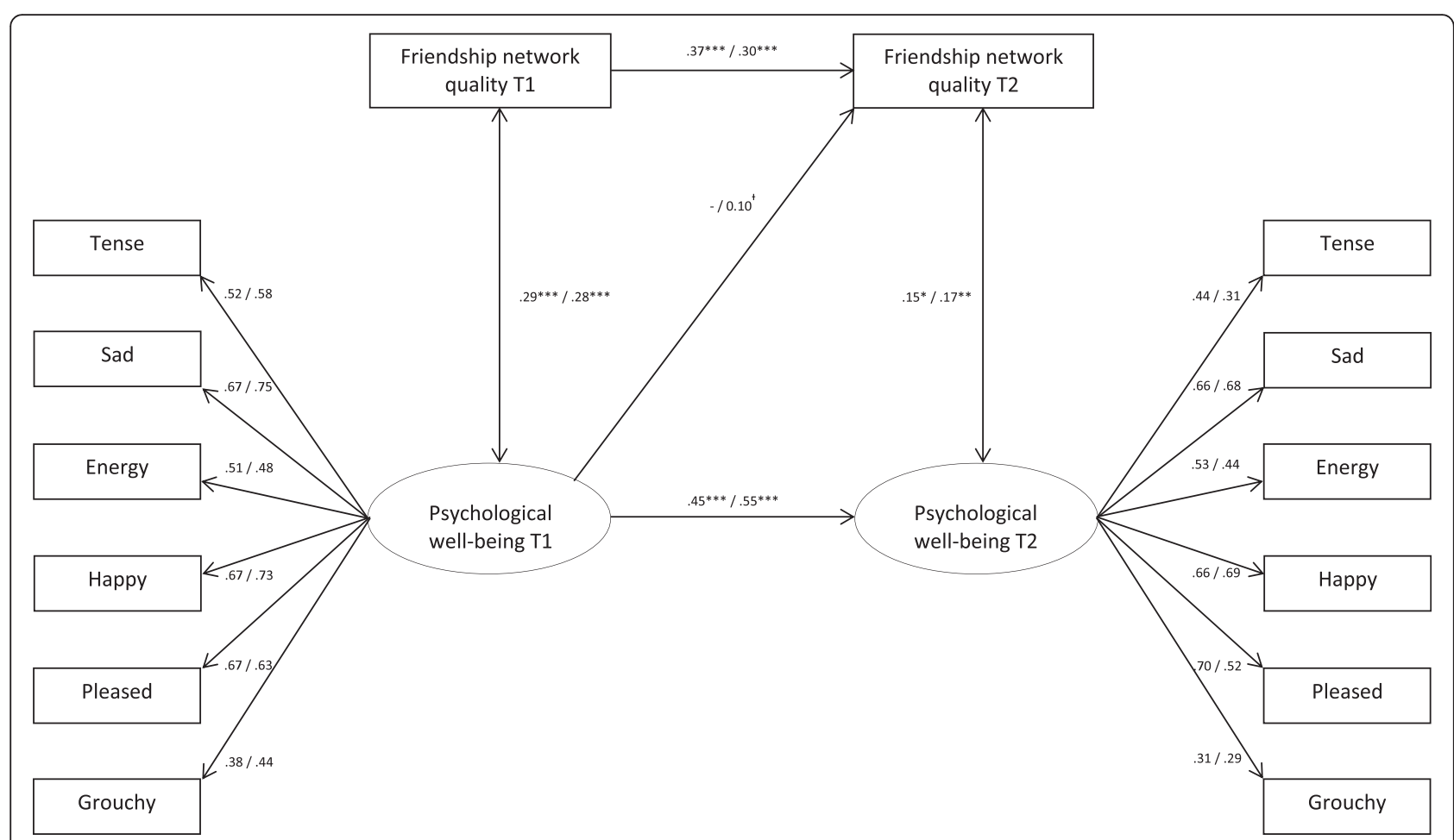

Fig. 2 The associations between friendship network quality and psychological well-being (Males $n=393$, Females $n=379$ ). Results from structural equation modeling. Estimates (standardized) are displayed as males/females. ${ }^{* *} p<.001,{ }^{* *} p<.01,{ }^{*} p<.05,{ }^{\dagger} p<.10$

who accumulate coping skills during adolescence [33], young males may be less equipped with such abilities when entering adulthood. Despite the slight improvement in relationship quality among females as well as a decrease in well-being with regard to some specific items among males over time, both dimensions remained fairly stable.

Based on the results from structural equation modeling - also taking into account the autoregressive associations - friendship network quality and psychological well-being was found to be positively correlated at each separate time point, confirming $\mathrm{H} 1$. The similar correlations between network quality and well-being for males and females are remarkable, refuting $\mathrm{H} 2$ and deviating from the prevailing theories about females' higher sensitivity to stress and difficulties in peer relationships [29]. It should also be noted that the correlation was significantly weaker at age 23 compared to age 19. From an induction perspective, this decrease in strength confirms previous research showing that peers exert a stronger influence on individuals during adolescence [41-43]. The weakened association may also underscore the stressful nature of adolescence [33] and hence adds support to the assumption that young people become increasingly resistant to peer influence when entering young adulthood [27]. Another explanation may be that young adults have developed more mature personality traits than 19-year-olds and have more settled life circumstances: 23-year-olds are about to complete their education and enter the labor market. Moreover, network settings of young adults are less rigidly structured compared to those of late adolescents. Whereas late adolescents' social relations are still framed by parental influences and the school environment, adult individuals are more sovereign in interacting with others from various social settings and thus have more options to diversify their friendships networks [44].

Referring to $\mathrm{H} 3, \mathrm{H} 4$, and $\mathrm{H} 5$, the examination of cross-lagged associations aimed to show whether network quality in late adolescence predicted well-being in young adulthood and/or whether well-being in late adolescence determined network quality in young adulthood. Goodness-of-fit statistics showed that the baseline model without any cross-lagged associations provided the best fit for males. As a result, $\mathrm{H} 3, \mathrm{H} 4$, and $\mathrm{H} 5$ were rejected for males. The social selection model was most suitable for the female sample and suggested a weak cross-lagged association of well-being at age 19 on network quality at age 23 , which confirms $\mathrm{H} 4$ for females. Given these results, we are also able to confirm H6, stating that there are gender differences in the directionality of associations between friendship network quality and psychological well-being. Drawing upon past research $[33,34]$, this may be because females whose well-being deteriorates over time are more likely to withdraw from or in other ways disrupt their social relationships. 
Notwithstanding, the associations between well-being and network quality may be a result of third variable influences. For example, underlying health problems associated with well-being and relationship quality may have confounded the association or imposed a selection effect. Chronic health problems and pain, information about which was unavailable in the present study, have been shown to restrict peoples' ability to participate in social activities [45]. As illustrated in Forgeron et al. [46], individuals with chronic pain tend to isolate rather than attempt to conceal their discomfort in social situations. Moreover, due to peers' lack of empathy about what it means to suffer from pain and health constraints, adolescents with chronic health problems are more subject to rejection and victimization by peers than those without such impairments [46, 47]. Other relationship characteristics may also determine well-being or may have operated as a confounder in the presented analysis. However, an earlier study identified'relationship quality' as strong determinant for well-being - being more important for well-being than other relationship aspects as for example trust to peers and self-disclosure [36].

\section{Strengths and limitations}

A particular strength of this study is the unique data sample that surveyed ego-centric network data at two points in time, making it possible to account for crosslagged and autoregressive pathways. The identified associations allow for conclusions about individuals in this particular age group, but it is reasonable to assume that they may also result in long-term consequences for the individuals' mental health later on in adulthood.

Some drawbacks have to be noted despite the strengths of data and analytical methods. The nonresponse rates are relatively high because of the sampling procedure. The study sample was indeed positively selected, and if the respondents who were lost to followup had more health problems and less supportive networks than those who responded, that may have resulted in an underestimation of the associations at age 23. The model-fit comparison between the baseline model and social selection model showed a $p$-value of .08 in favor of the social selection model. This indicates a trend rather than significance and somewhat weakens our conclusion to proceed with Model 3. Moreover, some unobserved individual and network characteristics are potentially underestimated, which may have confounded the findings. However, the model specification already considers the relevant aspects that contribute to the associations of interest, i.e., the cross-lagged associations between relationship quality and well-being. The inclusion of additional control variables would impede meaningful interpretation of the model.
As the present study was based on self-assessed variables, the respondents' misinterpretation of survey questions may have biased the outcomes. The same uncertainty also applies to structural aspects of peer relationships, such as the number of nominated alters. Although the number of friendships was taken into account when the measures were constructed, the respondents may have had more friends than they actually nominated. Limiting the possible number of peer nominations, however, restricts the study's focus on significant social relationships and puts greater emphasis on close peers in individuals' immediate social context. Friendship network quality was measured on a single dimension, with higher values representing higher relationship quality. Thus, the adverse effects from problematic relationships on well-being that were discussed in the introduction are not fully accounted for with this measure. Furthermore, accounting for average friendship quality may somewhat conceal the importance of high-quality friendships for well-being [48]. However, the present approach does acknowledge that female adolescents in particular have multiple friendships that provide a wider range of social support [49].

\section{Conclusions}

By drawing on previous research on social causation and social selection, the study provided empirical support for the notion that associations between relationship quality and psychological well-being - at least in females should be understood as result of cross-lagged associations between both dimensions.

This study has demonstrated that psychological wellbeing relates to perceived friendship quality, particularly in late adolescence. Although the correlation weakens when individuals enter young adulthood, the findings suggest that these dimensions should not be thought of as independent of each other. The mitigated association between network quality and well-being in young adulthood suggests that the importance of friendships for wellbeing decreases during the transition from late adolescence to young adulthood. Interventions that tackle reduced well-being and the increase of psychological symptoms would therefore seem more effective in adolescence than in adulthood. Moreover, despite the higher prevalence of low well-being among females, our findings suggest that the lack of high-quality friendships is associated with poor well-being among males as well. Still, we do not have sufficient knowledge about the causal pathways between networks and health, and whether these factors may differ by gender. Further research and policies focusing on these matters should therefore maintain a gender-specific approach when continuing to explore the interdependencies between psychological well-being and social network characteristics. 


\section{Acknowledgements}

This study was financially supported by the Swedish Council for Health, Working Life and Social Research, the Swedish Research Council, and the European Research Council.

\section{Availability of data and materials}

Because the data is linked to Swedish registers and subject to legal restrictions at Statistics Sweden, the full dataset used in this study is currently restricted to members of the LIFEINCON project. Specific requests for access to the survey part of the dataset should be addressed to the LIFEINCON PI at jens.rydgren@sociology.su.se.

\section{Authors' contributions}

AM designed the study and wrote the introduction and discussion section. YBA conceived and designed the study, performed the data analysis, and wrote the method and result section. MR, VÖ, JR and CE made substantial contributions by commenting on earlier versions of the manuscript. CE and JR conceived and designed the data set that was used in the study. All authors read and approved the final version of the manuscript.

\section{Competing interests}

The authors declare that they have no competing interests.

\section{Consent for publication}

Not applicable.

\section{Ethics approval and consent to participate}

The Ethical Review Board of Stockholm (2008/580-31) approved the study. Informed consent was obtained from each participant included in this study.

\section{Author details}

'Department of Sociology, Stockholm University, SE-106 91 Stockholm, Sweden. ${ }^{2}$ Centre for Health Equity Studies (CHESS), Stockholm University/ Karolinska Institutet, SE-106 91 Stockholm, Sweden. ${ }^{3}$ Department of Sociology, Lund University, SE-221 00 Lund, Sweden.

Received: 25 September 2015 Accepted: 7 June 2016 Published online: 11 July 2016

\section{References}

1. Smith KP, Christakis NA. Social networks and health. Annu Rev Sociol. 2008; 34:405-29.

2. Berkman LF, Glass T, Brissette I, Seeman TE. From social integration to health: Durkheim in the new millennium. Soc Sci Med. 2000;51:843-57.

3. Morrow V. Conceptualising social capital in relation to the well-being of children and young people: a critical review. Sociol Rev. 1999;47:744-65.

4. La Greca AM, Harrison HM. Adolescent peer relations, friendships, and romantic relationships: do they predict social anxiety and depression? J Clin Child Adolesc Psychol. 2005;34:49-61.

5. Nolen-Hoeksema S, Girgus JS. The emergence of gender differences in depression during adolescence. Psychol Bull. 1994;115:424-43.

6. Jenkins SR, Goodness K, Buhrmester D. Gender differences in early adolescents' relationship qualities, self-efficacy, and depression symptoms. J Early Adolesc. 2002;22:277-309.

7. van Beek Y, van Dolderen MSM, Demon Dubas JJS. Gender-specific development of nonverbal behaviours and mild depression in adolescence. J Child Psychol Psychiatry. 2006;47:1272-83.

8. Wiklund M, Malmgren-Olsson E-B, Öhman A, Bergström E, Fjellman-Wiklund A. Subjective health complaints in older adolescents are related to perceived stress, anxiety and gender-a cross-sectional school study in Northern Sweden. BMC Public Health. 2012;12:993.

9. Hagquist C. Discrepant trends in mental health complaints among younger and older adolescents in Sweden: an analysis of WHO data 1985-2005. J Adolesc Health. 2010;46:258-64.

10. Friberg P, Hagquist C, Osika W. Self-perceived psychosomatic health in Swedish children, adolescents and young adults: an internet-based survey over time. BMJ Open. 2012;2:e000681.

11. Gutman LM, Sameroff AJ. Continuities in depression from adolescence to young adulthood: contrasting ecological influences. Dev Psychopathol. 2004;16:967-84
12. Helsen $M$, Vollebergh $W$, Meeus W. Social support from parents and friends and emotional problems in adolescence. J Youth Adolesc. 2000; 29:319-35.

13. Ritter C. Social Supports, Social Networks, and Health Behaviors. In: Gochman DS, editor. Health Behavior: Emerging Research Perspectives. Boston, MA: Springer; 1998. p. 149-61.

14. Salmi P, Berlin M, Björkenstam E, Ringbäck Weitoft G. Psykisk ohälsa bland unga, Underlagsrapport till barns och ungas hälsa, vård och omsorg. Stockholm: Socialstyrelsen; 2013.

15. Bagwell CL. Friendship quality and perceived relationship changes predict psychosocial adjustment in early adulthood. J Soc Pers Relatsh. 2005;22:235-54.

16. Rose AJ, Carlson W, Waller EM. Prospective associations of co-rumination with friendship and emotional adjustment: considering the socioemotional trade-offs of co-rumination. Dev Psychol. 2007:43:1019-31.

17. Buote VM, Pancer SM, Pratt MW, Adams G, Birnie-Lefcovitch S, Polivy J, et al. The importance of friends: friendship and adjustment among 1st-year university students. J Adolesc Res. 2007;22:665-89.

18. Glick GC, Rose AJ. Prospective associations between friendship adjustment and social strategies: friendship as a context for building social skills. Dev Psychol. 2011;47:1117-32.

19. Biggs BK, Nelson JM, Sampilo ML. Peer relations in the anxiety-depression link: test of a mediation model. Anxiety Stress Coping. 2010;23:431-47.

20. Engels RC, ter Bogt T. Influences of risk behaviors on the quality of peer relations in adolescence. J Youth Adolesc. 2001;30:675-95.

21. Waldrip AM, Malcolm KT, Jensen-Campbell LA. With a little help from your friends: the importance of high-quality friendships on early adolescent adjustment. Soc Dev. 2008;17:832-52.

22. Furman W, Buhrmester D. Age and sex differences in perceptions of networks of personal relationships. Child Dev. 1992;63:103.

23. Hartup WW, Stevens N. Friendships and adaptation in the life course. Psychol Bull. 1997;121:355-70.

24. Way N, Greene ML. Trajectories of perceived friendship quality during adolescence: the patterns and contextual predictors. J Res Adolesc. 2006;16: 293-320.

25. Greca AML, Lopez N. Social anxiety among adolescents: linkages with peer relations and friendships. J Abnorm Child Psychol. 1998;26:83-94.

26. Parker JG, Rubin KH, Erath SA, Wojslawowicz JC, Buskirk AA. Peer relationships, child development, and adjustment: a developmental psychopathology perspective. In: Cicchetti D, Cohen DJ, editors. Developmental psychopathology. Vol 1 theory method. 2nd ed. New Jersey: Wiley; 2006. p. 419-93.

27. Steinberg L, Monahan KC. Age differences in resistance to peer influence. Dev Psychol. 2007;43:1531-43.

28. Borelli JL, Prinstein MJ. Reciprocal, longitudinal associations among adolescents' negative feedback-seeking, depressive symptoms, and peer relations. J Abnorm Child Psychol. 2006;34:154-64.

29. Rose AJ, Rudolph KD. A review of sex differences in peer relationship processes: potential trade-offs for the emotional and behavioral development of girls and boys. Psychol Bull. 2006;132:98-131.

30. Armsden GC, Greenberg MT. The inventory of parent and peer attachment: Individual differences and their relationship to psychological well-being in adolescence. J Youth Adolesc. 1987;16:427-54.

31. Kawachi I, Berkman LF. Social ties and mental health. J Urban Health. 2001; 78:458-67.

32. Selfhout MHW, Branje SJT, Meeus WHJ. Developmental trajectories of perceived friendship intimacy, constructive problem solving, and depression from early to late adolescence. J Abnorm Child Psychol. 2009;37:251-64.

33. Meadows SO, Brown JS, Elder GH. Depressive symptoms, stress, and support: gendered trajectories from adolescence to young adulthood. J Youth Adolesc. 2006:35:89-99.

34. Prinstein MJ, Borelli JL, Cheah CSL, Simon VA, Aikins JW. Adolescent girls' interpersonal vulnerability to depressive symptoms: a longitudinal examination of reassurance-seeking and peer relationships. J Abnorm Psychol. 2005;114:676-88.

35. Rose AJ. Co-rumination in the friendships of girls and boys. Child Dev. 2002; 73:1830-43

36. Almquist YB, Östberg V, Rostila M, Edling C, Rydgren J. Friendship network characteristics and psychological well-being in late adolescence: exploring differences by gender and gender composition. Scand J Public Health. 2014; $42: 146-54$ 
37. Löfgren J. Kalibreringsrapport, Bilaga 1. Örebro: Statistics Sweden; 2010.

38. Hu L, Bentler PM. Cutoff criteria for fit indexes in covariance structure analysis: conventional criteria versus new alternatives. Struct Equ Model Multidiscip J. 1999;6:1-55.

39. Kuha J. AIC and BIC: comparisons of assumptions and performance. Sociol Methods Res. 2004;33:188-229.

40. Adkins DE, Wang V, Dupre ME, Van den Oord EJ, Elder GH. Structure and stress: trajectories of depressive symptoms across adolescence and young adulthood. Soc Forces. 2009;88:31-60.

41. Steinberg L. Cognitive and affective development in adolescence. Trends Cogn Sci. 2005;9:69-74

42. Gardner M, Steinberg L. Peer influence on risk taking, risk preference, and risky decision making in adolescence and adulthood: an experimental study. Dev Psychol. 2005;41:625-35.

43. Dishion TJ, Tipsord JM. Peer contagion in child and adolescent social and emotional development. Annu Rev Psychol. 2011;62:189-214.

44. Barber BL, Eccles JS, Stone MR. Whatever happened to the jock, the brain, and the princess? Young adult pathways linked to adolescent activity involvement and social identity. J Adolesc Res. 2001;16:429-55.

45. Smith JA, Osborn M. Pain as an assault on the self: an interpretative phenomenological analysis of the psychological impact of chronic benign low back pain. Psychol Health. 2007;22:517-34

46. Forgeron PA, King S, Stinson JN, McGrath PJ, MacDonald AJ, Chambers CT Social functioning and peer relationships in children and adolescents with chronic pain: a systematic review. Pain Res Manag. 2010;15:27-41.

47. Forgeron PA, McGrath P, Stevens B, Evans J, Dick B, Finley AG, et al. Social information processing in adolescents with chronic pain: my friends don't really understand me. Pain. 2011;152:2773-80.

48. Birditt KS, Antonucci TC. Relationship quality profiles and well-being among married adults. J Fam Psychol. 2007;21:595-604.

49. Walen HR, Lachman ME. Social support and strain from partner, family, and friends: costs and benefits for men and women in adulthood. J Soc Pers Relatsh. 2000:17:5-30.

\section{Submit your next manuscript to BioMed Central and we will help you at every step:}

- We accept pre-submission inquiries

- Our selector tool helps you to find the most relevant journal

- We provide round the clock customer support

- Convenient online submission

- Thorough peer review

- Inclusion in PubMed and all major indexing services

- Maximum visibility for your research

Submit your manuscript at www.biomedcentral.com/submit

) Biomed Central 